\title{
Increasing-amplitude fatigue loading experiments to exam the effects of dynamic frequency on rock bridge fracturing revealed by acoustic emission and CT techniques
}

yu wang ${ }^{1}$, dayu long ${ }^{1}$, changhong $\mathrm{li}^{2}$, and jianqiang han ${ }^{3}$

${ }^{1}$ University of Science and Technology Beijing

${ }^{2}$ Affiliation not available

${ }^{3}$ Institute of Acoustics Chinese Academy of Sciences

June 9, 2020

\begin{abstract}
Real-time acoustic emission (AE) monitoring combined with post-test 3D computed tomography (CT) technique was employed to reveal the rock bridge fracturing behaviors of pre-flawed granite. Results show that the structural deterioration of rock bridge is strongly influenced by dynamic loading frequency. The strength, deformation, and fatigue lifetime of the pre-flawed granites are impacted by loading frequency. AE activities in the form of counts and energy increase with increasing loading frequency. In addition, AE spectral frequency analysis reveals six kinds of crack type, and the proportion of high frequency-high amplitude signal decreases, indicating that large-scaled cracks are prone to forming under high dynamic frequency. Moreover, post-test CT scanning visualizes fracturing pattern of rock bridge, a most striking finding is that complex crack network forms under high loading frequency. It is suggested that flaws are easy to be communicated for rock that subjected to low dynamic loading frequency conditions.
\end{abstract}

\section{Hosted file}

Effect of dynamic frequency on fracture evolution-6.9-submit.docx available at https: //authorea.com/users/299009/articles/458256-increasing-amplitude-fatigue-loadingexperiments-to-exam-the-effects-of-dynamic-frequency-on-rock-bridge-fracturing-revealedby-acoustic-emission-and-ct-techniques 